\title{
A Zinc-Finger-Family Transcription Factor, AbVf19, Is Required for the Induction of a Gene Subset Important for Virulence in Alternaria brassicicola
}

\author{
Akhil Srivastava, ${ }^{1}$ Robin A. Ohm, ${ }^{2}$ Lindsay Oxiles, ${ }^{1}$ Fred Brooks, ${ }^{1}$ Christopher B. Lawrence, ${ }^{3}$ \\ Igor V. Grigoriev, ${ }^{2}$ and Yangrae $\mathrm{Cho}^{1}$ \\ ${ }^{1}$ Plant and Environmental Protection Sciences, University of Hawaii at Manoa, 3190 Maile Way, St. John 317, Honolulu 96822 , \\ U.S.A.; ${ }^{2}$ United States Department of Energy Joint Genome Institute, 2800 Mitchell Drive, Walnut Creek, CA 94598, U.S.A.; \\ and ${ }^{3}$ Virginia Bioinformatics Institute and Department of Biological Sciences, Virginia Tech, Blacksburg 24061, U.S.A.
}

Submitted 26 October 2011. Accepted 2 December 2011.

\begin{abstract}
Alternaria brassicicola is a successful saprophyte and necrotrophic plant pathogen with a broad host range within the family Brassicaceae. It produces secondary metabolites that marginally affect virulence. Cell wall-degrading enzymes (CDWE) have been considered important for pathogenesis but none of them individually have been identified as significant virulence factors in $A$. brassicicola. In this study, knockout mutants of a gene, AbVf19, were created and produced considerably smaller lesions than the wild type on inoculated host plants. The presence of tandem zinc-finger domains in the predicted amino acid sequence and nuclear localization of AbVf19. reporter protein suggested that it was a transcription factor. Gene expression comparisons using RNA-seq identified 74 genes being downregulated in the mutant during a late stage of infection. Among the 74 downregulated genes, 28 were putative CWDE genes. These were hydrolytic enzyme genes that composed a small fraction of genes within each family of cellulases, pectinases, cutinases, and proteinases. The mutants grew slower than the wild type on an axenic medium with pectin as a major carbon source. This study demonstrated the existence and the importance of a transcription factor that regulates a suite of genes that are important for decomposing and utilizing plant material during the late stage of plant infection.
\end{abstract}

Alternaria brassicicola is the causal agent of black spot disease of cultivated brassicas, such as cabbage, canola, and mustard. It has also been used in studies of host-pathogen interactions on Arabidopsis (Oh et al. 2005; Thomma et al. 1999). Pathogenesis in necrotrophic fungi is generally described as a two-step process of initially killing host cells directly (necrosis) or inducing programmed cell death with toxins, followed by or in conjunction with decomposing tissues with cell walldegrading enzymes (CWDE).

Nucleotide sequence data for AbVf19 (Alternaria brassicicola virulence factor 19) is available in the GenBank database under accession number JN835469 and RNA-seq data GEO Series accession number GSE33148.

Corresponding author: Y. Cho; E-mail: yangrae@ hawaii.edu; Telephone: +1.808 .956 .5305 ;

* The $\boldsymbol{e}$-Xtra logo stands for "electronic extra" and indicates three supplementary figures and three supplementary tables are published online and Figure 6 appears in color online.
The importance of toxins in disease development has been clearly demonstrated in other plant-pathogen systems with necrotrophic fungi (Churchill et al. 1995; Ciuffetti et al. 1997; Del Sorbo et al. 2000; Yun et al. 1998). Several A. alternata pathotypes produce toxic, host-specific secondary metabolites synthesized by polyketide synthases or nonribosomal peptide synthases that are pathogenicity factors (Ito et al. 2004; Johnson et al. 2000; Spassieva et al. 2002; Tanaka et al. 1999). Several secondary metabolites and proteins in A. brassicicola have been identified as toxins, such as the polyketide depudecin (Wight et al. 2009), the diterpenoid brassicenes (Hashimoto et al. 2009), Brassicicolin A (Pedras et al. 2009a), and two proteins (Oka et al. 2005; Otani et al. 1998). All toxins produced by $A$. brassicicola, however, are modest virulence factors that only marginally affect pathogenesis.

The importance of CWDE genes in virulence has been supported by the identification of mutants with impaired derepression mechanisms of carbon catabolite repression in Cochliobolus carbonum and Fusarium oxysporum (Ospina-Giraldo et al. 2003; Tonukari et al. 2000). Mutation of the sucrose nonfermenting factor 1 (SNF1) homolog showed severely reduced virulence in these two fungi. It has been speculated that coordinated expression of many CWDE genes is needed for successful pathogenesis. In contrast, mutants of the homologous gene $A b S n f l$ and its downstream gene, $A b C r e A$, were as virulent as the wild type (Cho et al. 2009). These findings suggested that $A$. brassicicola uses a different regulatory mechanism for expression of CWDE genes during pathogenesis.

No single CWDE has been identified as important for pathogenesis in A. brassicicola despite knockout of over a dozen individual genes predicted to encode lipases, pectate lyases, cutinases, xylanases, and proteases (Y. Cho and C. B. Lawrence, unpublished results). Furthermore, inefficient utilization of $\mathrm{xy}$ lan due to loss of the transcription factor $A b X \ln R$ that regulates the multiple xylanase genes did not affect virulence (Cho et al. 2009). Slow growth of a deletion mutant of the pathogenicity factor gene AbSte12, with pectin as a major carbon source, suggested that this gene was necessary for the induction of pectin digestion enzymes. Its upstream mitogen-activated protein kinase gene, Amkl, was necessary for the induction of several hydrolytic enzyme-coding genes (Cho et al. 2007).

In addition to the loss of pathogenicity, mutation of Ste12 homologs caused developmental defects such as impaired conidia maturation in most pathogenic fungi, including $A$. brassicicola (Cho et al. 2009; Wong Sak Hoi and Dumas 2010). Mutants of the Amkl gene (amkl) showed more severe phenotypes 
than those of $\Delta a b s t e 12$. The highly pleiotropic nature of $\Delta a b s t e 12$ and amkl mutants made it difficult to interpret the importance of CWDE genes in pathogenesis. To date, no transcription factors have been identified that regulate CWDE genes during pathogenesis without affecting fungal development. In this study, we identified mutants that exhibited severely reduced virulence but did not show developmental defects. Our study provides an example of a zinc-finger-family

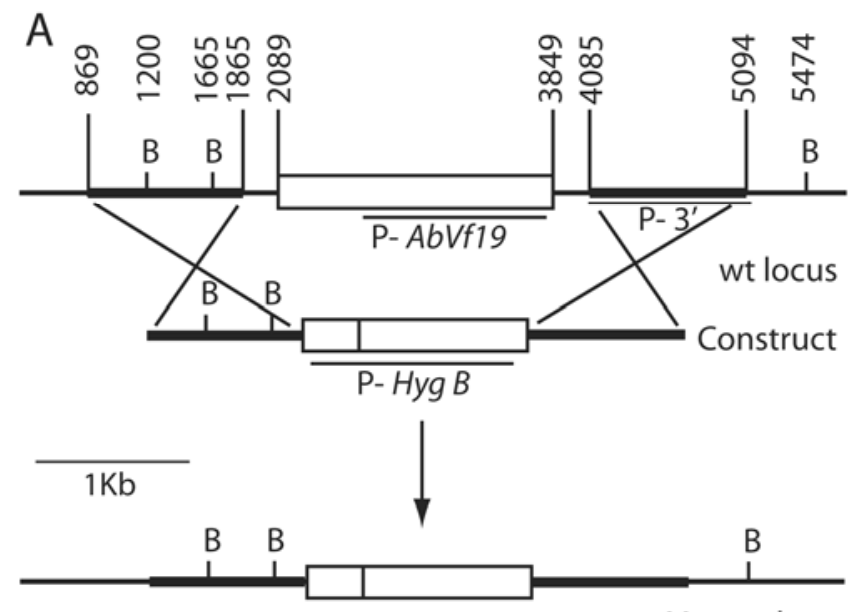

Mutant locus

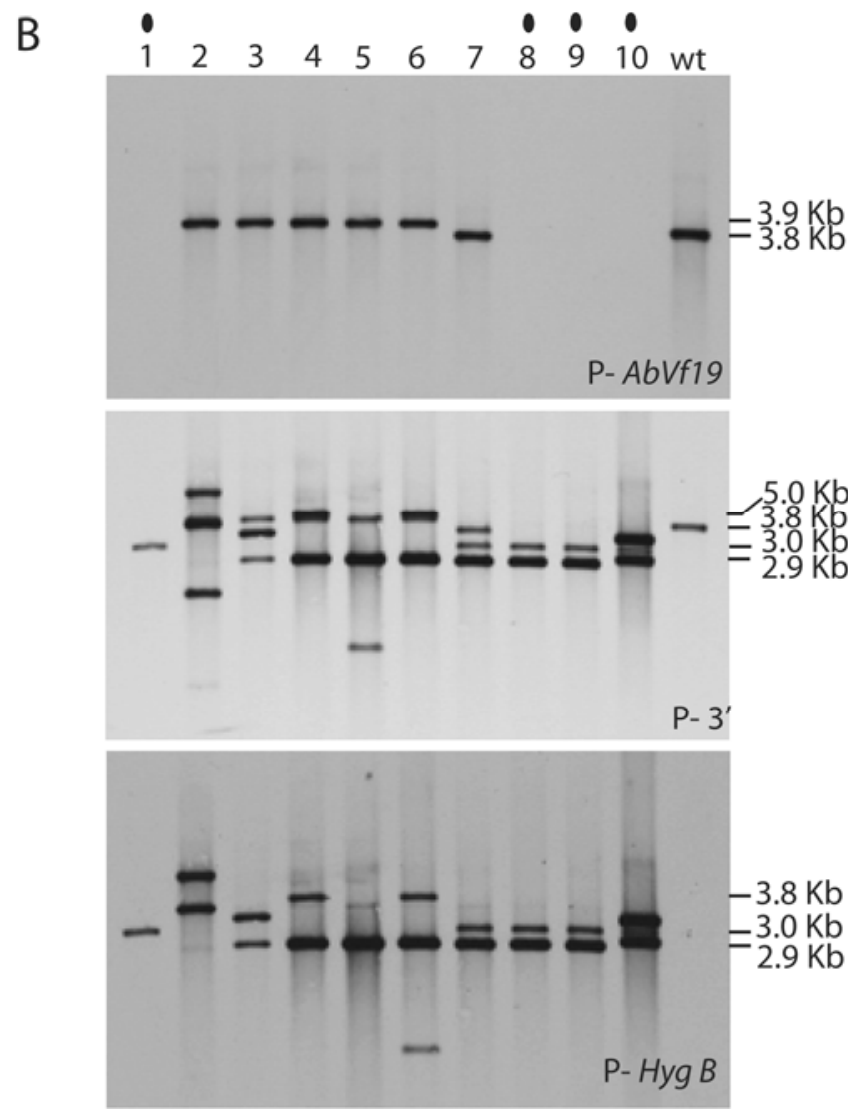

Fig. 1. Deletion of the $A b V f 19$ gene. A, Schematic diagram of the wildtype (wt) locus, replacement construct, and mutant locus are shown in order. The mutant locus represents a scenario of replacement of the coding region of the $A b V f 19$ gene by a single copy of a selectable marker hygromycin B transferase $(H y g B)$ cassette. $\mathbf{B}$, Lane 1 shows replacement of the gene by a single copy. Lanes 8,9 , and 10 show replacement of the gene by multiple copies of the replacement constructs. Dots $(\bullet)$ indicate DNA lanes for pathogenicity assay results presented in this study. Probe regions are marked by P-AbVf19, $\mathrm{P}-3^{\prime}$, and $\mathrm{P}-H y g$ B. $\mathrm{B}=$ Bam HI enzyme digestion site. transcription factor gene that plays a critical role in regulating virulence by coordinated expression of a suite of genes, including putative CWDE genes, in the necrotrophic plant pathogen A. brassicicola.

\section{RESULTS}

\section{Disruption mutants of the $A b V f 19$ gene.}

We systematically created mutants for over 200 genes by a single homologous recombination-based gene disruption method described previously (Cho et al. 2006). During our pathogenicity assays of the knockout mutants, we discovered one gene whose mutants showed a $90 \%$ decrease in virulence. The gene of interest was predicted to encode 564 amino acids with nuclear localization signals (probability 95\%) at two locations predicted by PSORT (Horton and Nakai 1997) and two $\mathrm{C}_{2} \mathrm{H}_{2-}$ zinc-finger domains (Pfam ID: PF00096) (Bateman et al. 2004). Only one copy of the gene was predicted to be present in the draft genome sequence of A. brassicicola. The tandem putative DNA-binding domains are highly conserved among fungi in the phylum Ascomycota, including Saccharomyces cerevisiae (Supplementary Fig. S1). All ascomycete fungi in the Pezizomycotina with genome sequences publically available had a homolog in their genomes (Supplementary Fig. S2). Its homolog was involved in but not essential for the osmotic stress response in Trichoderma atroviride (Seidl et al. 2004). The functions of its homolog were annotated as a hypothetical protein in most fungal genomes and as a cutinase G-box binding protein in four genomes, but without experimental evidence. We named this gene AbVf19 (A. brassicicola virulence factor 19).

\section{Replacement of the $A b V f 19$ gene with a HygB cassette.}

We created additional null mutants of AbVf19 by replacing the coding region with a hygromycin B transferase (HygB) gene cassette. Southern hybridization with three probes against the genomic DNA extracted from 11 transformants and purified by single-spore isolation confirmed that the AbVf19 gene was absent in 4 of 11 transformants (Fig. 1). The AbVf19 coding region was replaced by a single copy of the HygB resistance cassette in one mutant $(\triangle a b v f 19-1)$ and by multiple copies in three gene-deletion mutants ( $\triangle a b v f 19-8, \Delta a b v f 19-9$, and $\triangle a b v f 19-10)$.

\section{Decreased virulence \\ of the $\Delta a b v f 19$ mutants on green cabbage.}

We performed pathogenicity assays to further characterize virulence attributes associated with AbVf19. All four deletion mutants produced significantly smaller lesions $(P<0.001)$ than the wild type (77 to $92 \%$ ) in each assay using various concentrations of inoculum on detached leaves (Table 1). The mutants consistently produced smaller lesions at concentrations of 1,000 and 2,000 conidia compared with the wild type (Fig. 2A). The relative reduction in virulence was slightly less with 2,000 conidia on detached leaves. To conservatively estimate mutation effects on virulence, we used 2,000 conidia for the pathogenicity assays on whole plants to compare the lesions produced by the wild type and $\Delta a b v f 19$. The lesions produced by $\Delta a b v f 19-1$ were similarly reduced compared with the wild type on whole plants (Fig. 2B); therefore, we used detached leaves in the rest of our assays for speed and convenience. We also compared lesions produced by the wild type, $\Delta a b v f 19$ mutant, and a mutant complemented with a wild-type allele ( $\triangle a b v f 19: A b V f 19)$. Lesions produced by the complemented mutant were similar to those produced by the wild type, while the $\Delta a b v f 19$ mutant showed a severe reduction in virulence as evidenced by the smaller lesions (Fig. 2C). 


\section{No difference in germination and appressorium-like structure formation.}

We compared spore germination between the $\Delta a b v f 19-1$ and the wild-type strains on minimal medium agar (MMA) and potato dextrose agar (PDA). Germination for both the mutant and wild type $3 \mathrm{~h}$ after inoculation on the two types of media was approximately $100 \%$. The length of germ tubes was highly variable within each group (wild type and mutant). There was no statistical difference in average length between the mutant and wild-type germ tubes on MMA or PDA (Fig. 3A).

Germination was slower on Brassica oleracea (green cabbage) than on synthetic media for the wild type and the $\Delta a b v f 19$ mutant. Germination rates for both were approximately $50 \%$ at $12 \mathrm{~h}$ postinoculation (hpi) and $100 \%$ at $24 \mathrm{hpi}$ (Fig. 4). Germ tube length on host plant leaves varied within each group but average length was similar between the two groups at 12 hpi. The mutant and wild type formed small, swollen structures (appressorium-like structures hereafter) at the tips of germ tubes at a similar frequency by 24 hpi (Fig. 5).

\section{Expression and localization of AbVf19 protein.}

To survey the expression and localization of the AbVf19 protein, we tagged its gene at the $\mathrm{C}$-terminus, right before the stop codon, with a green fluorescent protein (GFP) coding sequence (Lorang et al. 2001). The tagging construct was designed for the GFP protein to be expressed as a fusion protein with an $A b V f 19$ gene that was regulated by its native promoter elements. As a negative control, we also made mutants that expressed GFP regulated by an Amrlpromoter (Y. Cho, unpublished data). All GFP signals in the negative control mutant remained in the cytoplasm (Fig. 5A). In contrast, the GFP signals were located in the nuclei of the mutant expressing AbVf19-GFP fusion proteins (Fig. 5B and C). The AbVf19GFP protein was expressed and located in the nuclei of all fungal tissues during all stages of host infection from 24 to $96 \mathrm{hpi}$. The AbVf19-GFP protein was also expressed in hyphae during growth in axenic media, although it was expressed at a lower level than during plant infection.

\section{Genes regulated by $A b$ Vf19.}

To study the regulatory roles of AbVf19 in A. brassicicola, we compared gene expression profiles between the wild type and the $\Delta a b v f 19$ mutant at $96 \mathrm{hpi}$, a late stage of infection, using an RNA-seq approach. In total, 27 and 74 genes among A. brassicicola's 10,688 predicted genes were significantly upor downregulated, respectively, more than twofold $(P<0.05)$ in the $\triangle a b v f 19$ mutant compared with the wild type (Supplementary Table S1). This represents 0.25 and $0.69 \%$ of the predicted genes, respectively, in the current A. brassicicola genome. Functional categories that were overrepresented in the downregulated genes included 15 glycoside hydrolases, 6 pectate lyases, and 6 peptidases (Supplementary Table S2). In addition, one of nine cutinases was also downregulated 73 times. In total, 27 genes were upregulated in the mutant. These genes included one pectate lyase and three glucoside hydrolase genes in contrast to the six other pectate lyase and 14 glucoside hydrolate genes that were downregulated. We examined the reliability of the gene expression data produced by RNA-seq with quantitative real-time polymerase chain reaction (qRTPCR), using three differentially expressed genes and two nondifferentially expressed genes. The qRT-PCR results were very similar to the RNA-seq data.

\section{Conserved sequence motifs shared among downstream genes.}

To discover common motifs at the putative promoter region among downregulated genes in the mutant, we surveyed the putative promoter regions of genes with expression values over 300 mapped fragments per kilobase of exon model per million (FPKM) in wild-type A. brassicicola and below 100 FPKM in $\triangle a b v f 19$. Nine genes matched these criteria. Comparison of the promoters of these genes revealed a conserved motif shared by all nine genes (Fig. 6). Next, occurrences of the same motif were counted within the promoter regions of 56 other downregulated genes in the mutant. Of the 56 genes, 17 had at least one conserved motif in their promoter region. The occurrence of

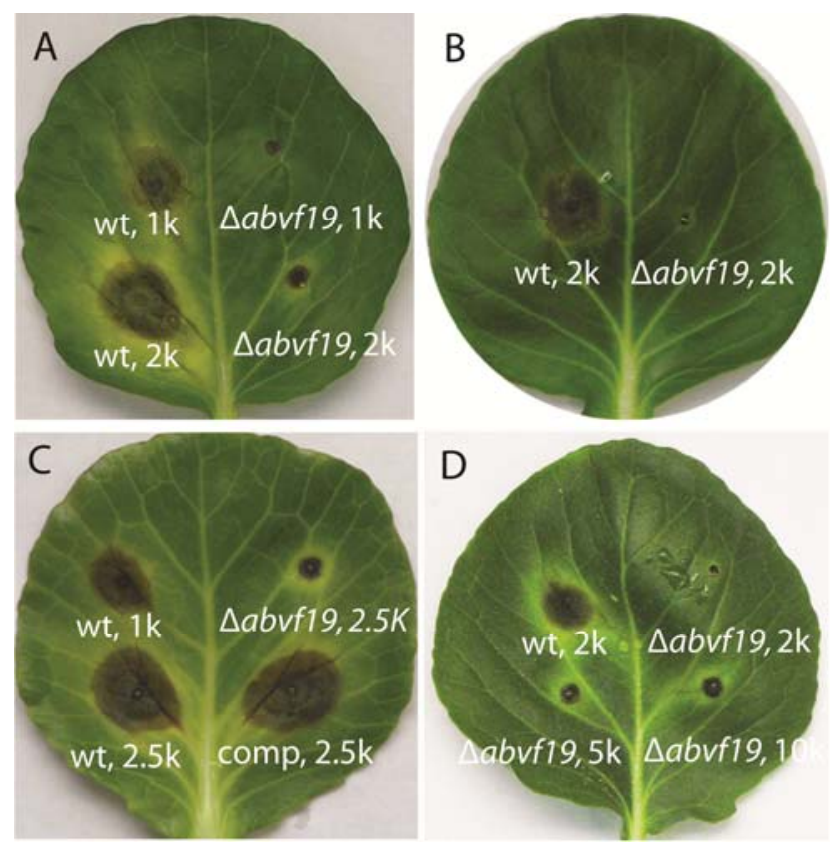

Fig. 2. Decreased virulence of $\triangle a b v f 19$ mutants on host plants (Brassica oleracea). A, Lesions on B. oleracea 5 days after inoculation with 1,000 or 2,000 conidia of the wild type and $\Delta a b v f 19-1$ mutant on a detached leaf. B, One leaf showing lesions produced by 2,000 conidia of the wild type and $\triangle a b v f 19-1$ mutant on a whole plant. The leaf was detached and photographed at the end of the assay. $\mathbf{C}$, Similar lesion size produced by a complemented mutant and the wild type compared with the small lesions produced by the $\triangle a b v f 19$ mutant. D, Lesions produced by 2,000 conidia of the wild type (top left) and 2,000, 5,000, and 10,000 conidia of a $\triangle a b v f 19$ mutant. wt $=$ wild-type Alternaria brassicicola; $\Delta a b v f 19=$ AbVfl19 deletion mutant; compl = mutant complemented with a native allele of the AbVf19 gene ( $\triangle a b v f 19: A b V f 19)$.

Table 1. Decreased virulence of four strains of $\Delta a b v f 19$ deletion mutants compared with wild-type Alternaria brassicicola

\begin{tabular}{|c|c|c|c|c|c|c|}
\hline \multirow[b]{2}{*}{ Mutants } & \multirow[b]{2}{*}{ Number of spores (wt/mut) } & \multirow[b]{2}{*}{$d f$} & \multicolumn{2}{|c|}{ Lesion size (mm) } & \multirow[b]{2}{*}{ Virulence decrease $(\%)$} & \multirow[b]{2}{*}{$P$} \\
\hline & & & Wild type & Mutant & & \\
\hline$\Delta a b v f 19-1$ & $1,800 / 1,900$ & 8 & $19.6 \pm 2.6$ & $4.3 \pm 3.2$ & 78 & 4.0E-09 \\
\hline$\triangle a b v f 19-1 *$ & $2,000 / 2,000$ & 8 & $10.4 \pm 5.3$ & $0.9 \pm 0.9$ & 92 & 7.0E-05 \\
\hline$\triangle a b v f 19-8$ & $2,000 / 2,025$ & 8 & $9.2 \pm 4.6$ & $2.1 \pm 3.0$ & 77 & $1.0 \mathrm{E}-04$ \\
\hline$\Delta a b v f 19-10$ & $2,000 / 2,025$ & 8 & $9.4 \pm 4.5$ & $1.8 \pm 1.9$ & 81 & 8.0E-04 \\
\hline
\end{tabular}

a Abbreviations: $\mathrm{wt}=$ wild type, mut $=$ mutant, $d f=$ degrees of freedom, and $P=$ probability. Lesion size indicates the average lesion diameter. Results marked with an asterisk $(*)$ were from pathogenicity assays on whole plants, others were from assays with detached leaves. 
this motif among the 56 promoters was significantly greater than can be randomly selected from a pool of 1,071 promoters with this motif among a total of 8,274 promoters $\left(P=5 \times 10^{-4}\right)$. The motif showed similarity to the previously described binding site of a zinc-finger transcription factor in the JASPAR CORE database (MA0036.1, $P=4 \times 10^{-3}$ ). The cutinase-encoding gene $C u t A b 1$ that expressed 73 times more transcripts in the wild type than in the mutant had two copies of the putative binding motif whereas the other eight cutinase genes did not have this motif.

\section{Plant responses.}

The sequence tags used to identify differentially expressed genes in the $\Delta a b v f 19$ mutant and wild-type A. brassicicola were also aligned to 14,000 full-length cDNA sequences of $B$. oleracea. Several putative defense-related genes were highly expressed in plants that were inoculated with either the wild type or the mutant. They consisted of genes annotated as lectin domain-containing protein, pathogenesis-related protein 1 , reticulin oxidase-like protein, psi-producing oxygenase, cytochrome P450, and D-glucan cellobiohydrolase. In our analysis, however, no plant genes in the 14,000-gene set were identified as being differentially expressed when challenged by the wild type or the $\triangle a b v f 19$ mutant.

\section{Reduced virulence in Arabidopsis PAD3 mutants.}

Gene expression profiles at the late stage of infection suggested that the reason for the decrease in virulence of $\Delta a b v f 19$
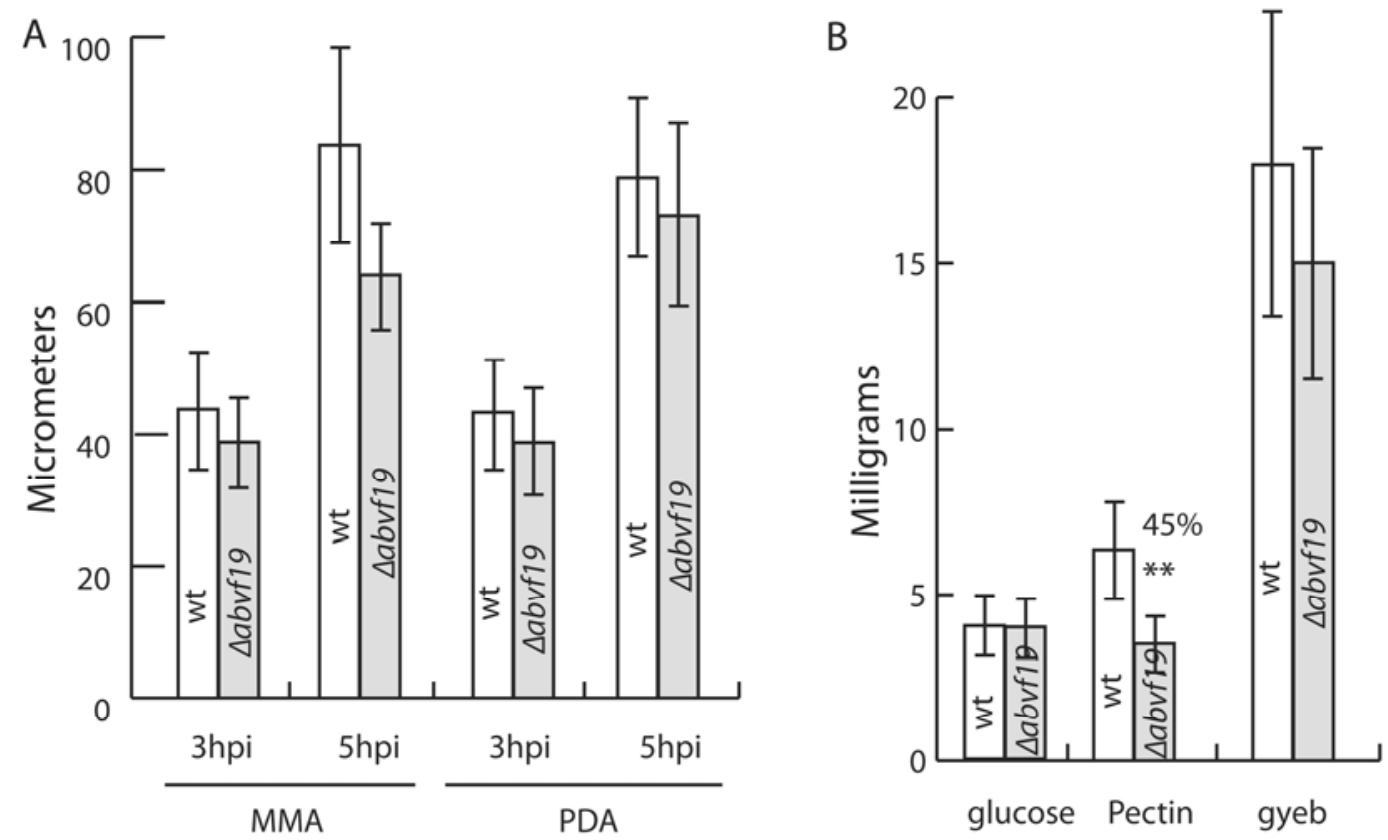

Fig. 3. Comparisons of vegetative growth between the $\Delta a b v f 19$ mutant and wild-type Alternaria brassicicola. A, Length of germ tubes on two different media measured at 3 and $5 \mathrm{~h}$ postinoculation. B, Effect of pectin on vegetative growth of the $\Delta a b v f 19$ mutant and wild type. Bars represent dry weight of mycelia in milligrams. Error bars represent standard deviation in both charts. $\mathrm{wt}=$ wild type, MMA $=$ minimal media agar, $\mathrm{PDA}=$ potato dextrose agar, $* *=P<0.01$.
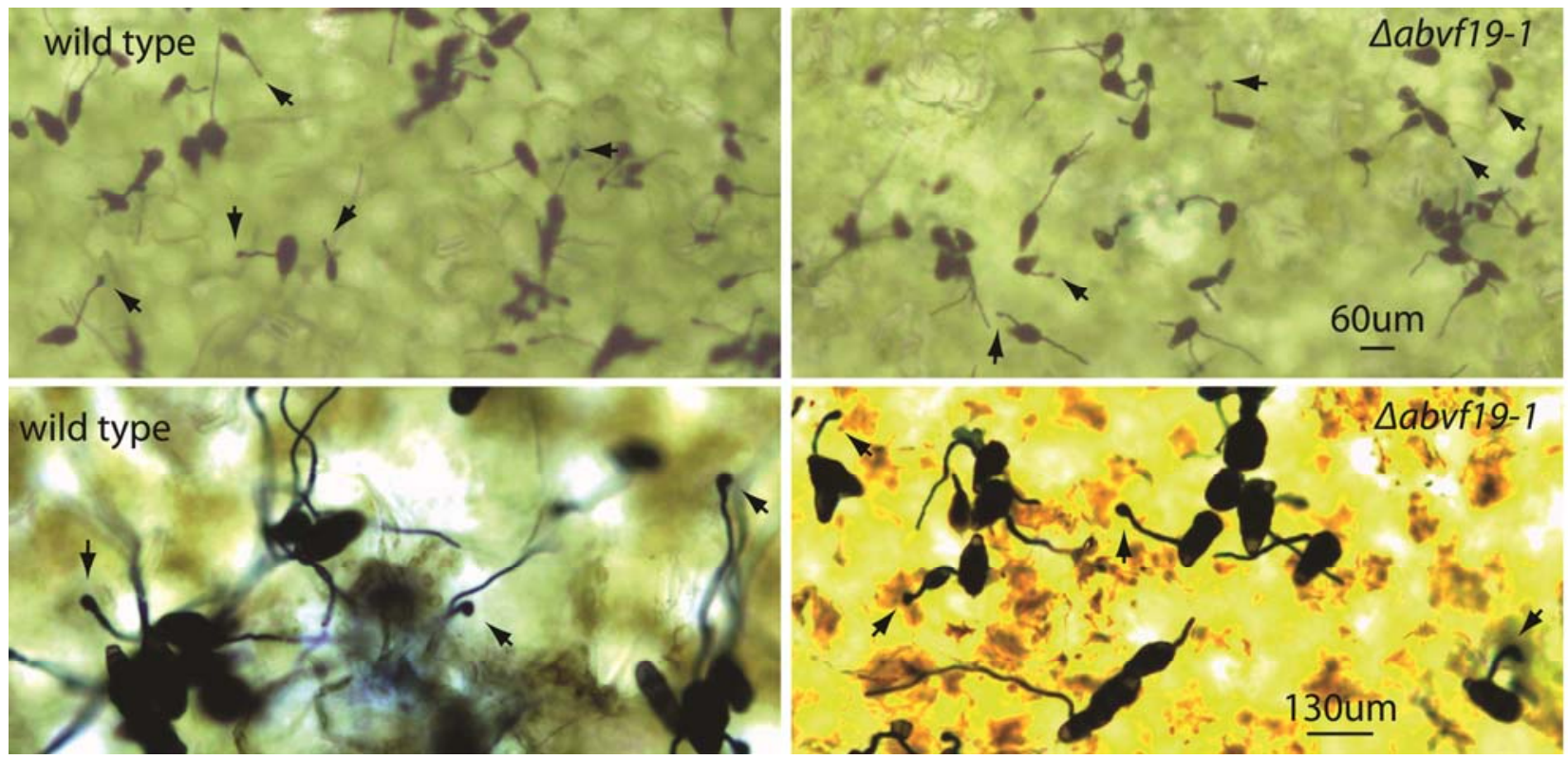

Fig. 4. Germination and formation of appressorium-like structures. Images represent infection courts at $24 \mathrm{~h}$ postinoculation by the wild type (left) and $\triangle a b v f 19$ mutant (right). Fungal tissues were stained with Trypan blue. Appressorium-like structures are marked with arrows. 
was the reduced expression of several enzymes putatively important for depolymerization of plant material. We compared the virulence of the $\Delta a b v f 19$ mutants on the pad 3 mutant and the wild-type Arabidopsis thaliana to test the effects of a lack
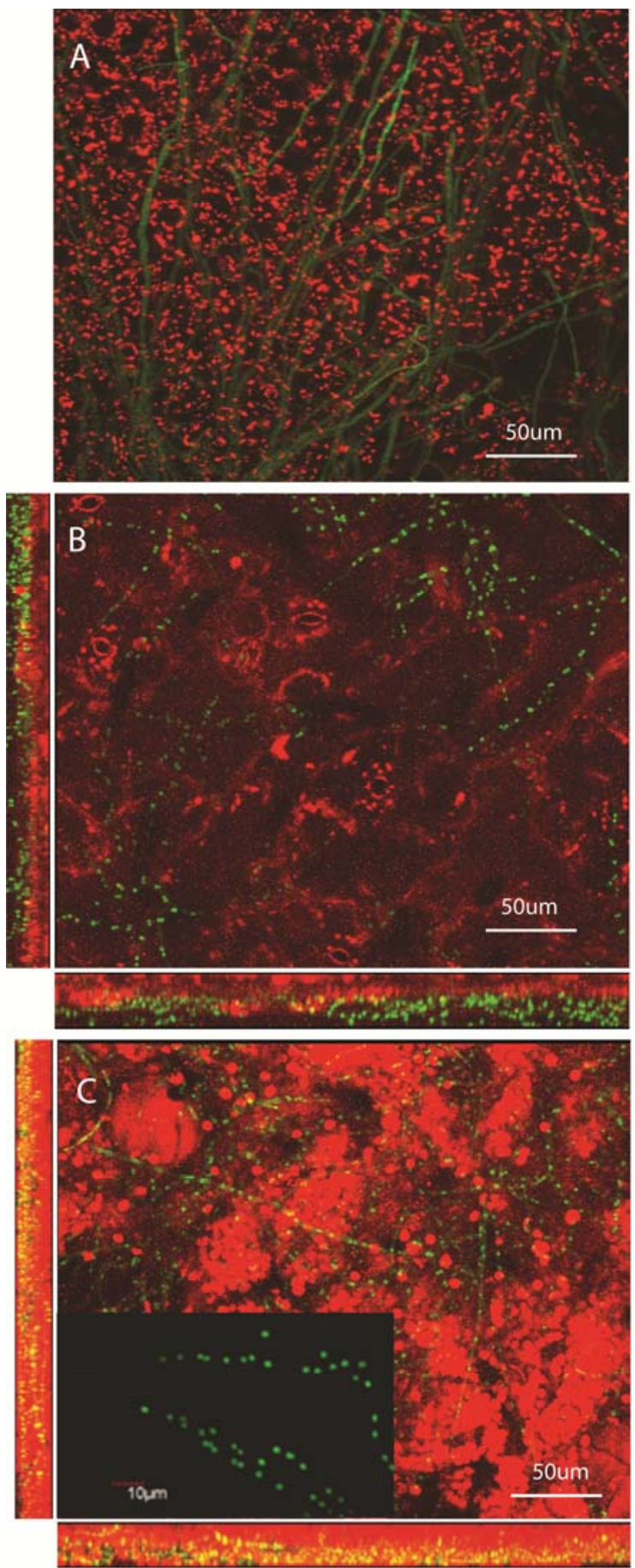

Fig. 5. Confocal microscopic images showing AbVf19 protein expression and localization during pathogenesis. A, Negative control of green fluorescent protein (GFP) localization. Composite image of green fluorescence representing GFP and pink autofluorescence representing chloroplasts in plant tissues. B, Green fluorescence represents AbVf19-GFP fusion protein $24 \mathrm{~h}$ postinoculation. The green fluorescence signal is variable because fungal hyphae are imbedded in plant tissues. Deeply imbedded signals appear weaker than those on the plant surface. X- and Y-axis rotation views provide a sense of the depth of fungal penetration. C, Infected plant tissue was squashed to get a better view of penetrating fungal hyphae at $96 \mathrm{~h}$ postinoculation. The inset picture shows nuclear localization of green fluorescence. of phytoalexin and the delayed response of plant resistance genes on the severe reduction of the mutant's virulence. We expected that pad3 plants were very susceptible to $\Delta a b v f 19$ if $A b V f 19$ was associated with detoxification of the camalexin (the Discussion section discusses reasons). The $\Delta a b v f 19 \mathrm{mu}-$ tant, however, failed to cause lesions or was only weakly virulent on pad3 plants, such as on wild-type A. thaliana. Lesion size caused by the wild-type Alternaria brassicicola was a little smaller on the wild type than on the pad3 mutant Arabidopsis thaliana (Fig. 7).

\section{Inefficient use of pectin by the mutant.}

To determine the reason for reduced virulence in the mutant, fungal growth rates were compared in axenic broth media containing different carbon sources. We grew the mutants and wild type in a minimal medium broth supplemented with glucose as a major carbon source. Biomass, measured as dry mycelial weight, was similar for the mutant and the wild type (Fig. 3B), suggesting that glucose did not affect vegetative growth of the mutant. Both $\Delta a b v f 19$ and wild-type Alternaria brassicicola grew very slowly in the presence of $\alpha$-cellulose or xylan as a major carbon source; thus, we did not investigate their effect on mutant growth. Both the wild type and the mutant produced almost $300 \%$ more mycelial biomass in glucose-yeast extract broth (GYEB) than in a minimal medium supplemented with glucose. The difference between the two in GYEB was not statistically significant. Notably, there was a significant difference when a pectin supplement was added to the minimal medium. The biomass of the wild type increased by $58 \%$ while the mutant biomass decreased by $11 \%$. The mutant grew significantly less than the wild type $(P=0.0012$, $d f=3$ ) with pectin as the major carbon source.

\section{DISCUSSION}

Multiple strains of disruption and deletion mutants of the AbVf19 gene consistently displayed an approximately $90 \%$ reduction in virulence compared with wild-type $A$. brassicicola. The reduced virulence was restored by complementing a $\Delta a b v f 19$ mutant with the wild-type allele of its AbVf19 gene. These pathogenicity assay results showed that the severe reduction of virulence in the mutants was due to the loss of the AbVf19 functions.

The predicted amino acid sequence of the AbVf19 protein contains nuclear localization signals and tandem $\mathrm{C}_{2} \mathrm{H}_{2}$-zincfinger domains (Pfam ID: PF00096) (Bateman et al. 2004).

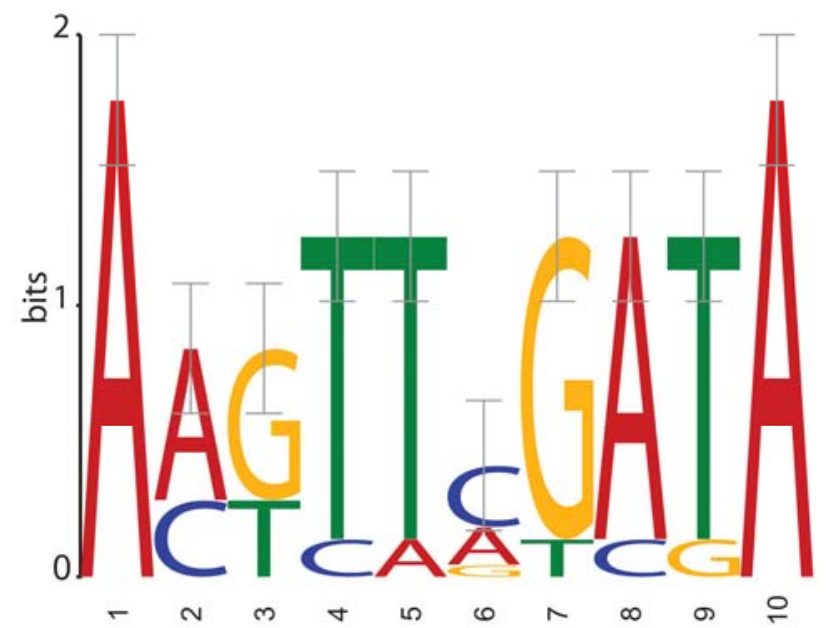

Fig. 6. Putative transcription factor binding site. This motif is overrepresented in promoters among the downregulated genes in $\Delta a b v f 19$ mutants. 
The nuclear localization of AbVf19 protein was confirmed by accumulated green fluorescence signals from AbVf19-GFP fusion proteins. The $\mathrm{C}_{2} \mathrm{H}_{2}$-zinc finger is best known for its binding in the major groove of DNA and is typically spaced at 3-bp intervals. The $\alpha$-helix expanding two conserved histidines in each domain can make sequence-specific contacts to DNA bases (Iuchi 2001). The accumulation of AbVf19 proteins in nuclei and the presence of DNA-binding motifs in the predicted amino acid sequence indicated that AbVf19 is a transcription factor.

\section{Mechanisms of reduced virulence in the $\Delta a b v f 19$ mutant.}

The $\Delta a b v f 19$ mutant expressed fewer transcripts for 74 genes than wild-type $A$. brassicicola during the late stage of infection, as was made evident initially by RNA-seq experiments. Among these 74 downregulated genes, 26 hydrolytic enzyme genes were overrepresented. Their predicted functions suggested depolymerization of cell wall components or extracellular proteins. Although we cannot rule out the possible importance of other genes, the 74 genes included neither peroxisomal enzymes such as catalases or dismutases, nor detoxification enzymes such as glucosyltransferase genes (Sexton et al. 2009) and dithiocarbamate hydrolase (Pedras et al. 2009b). The gene expression comparisons between the mutant and wild-type $A$.
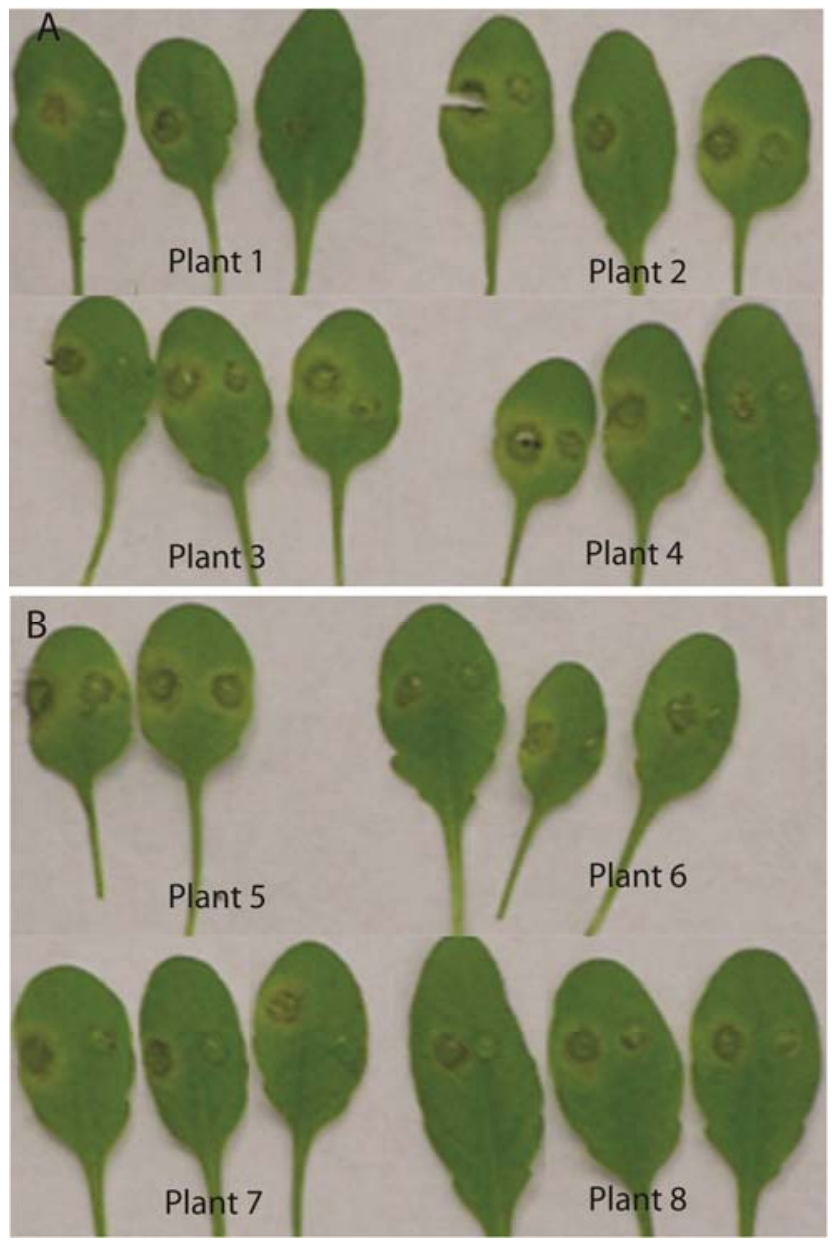

Fig. 7. Decreased virulence of $\triangle a b v f 19$ mutants on Arabidopsis thaliana. A, Lesions caused by approximately 2,000 conidia of the $\Delta a b v f 19-1$ mutant and the wild-type Alternaria brassicicola on whole plants of wildtype Arabidopsis thaliana (Col-0). B, Lesions caused by the wild type and $\triangle a b v f 19-1$ mutant on whole plants of the pad3 mutant of A. thaliana (Col-0 background). The leaf was detached and photographed at the end of the assay. The wild type and $\Delta a b v f 19-1$ mutant were inoculated on the left and right side of the leaf midvein, respectively. brassicicola suggested that inefficient detoxification of reactive oxygen species or phytoalexins in the host plant was not the main cause for the decrease in $\Delta a b v f 19$ mutant virulence.

The pad3 mutant does not produce the phytoalexin camalexin and is more susceptible to wild-type A. brassicicola (Narusaka et al. 2003; Zhou et al. 1999). The $\Delta a b v f 19$ mutant was expected to be more virulent on the pad3 mutant than on the Col-0 ecotype if the $\Delta a b v f 19$ mutant could not detoxify camalexin. The $\Delta a b v f 19$ mutant, however, was equally less virulent on the phytoalexin-deficient pad3 and wild-type Arabidopsis thaliana. Likewise, there was no difference in the gene expression profile of $B$. oleracea in response to the $\Delta a b v f 19$ mutant or wild-type Alternaria brassicicola. These two independent data consistently suggested that the reduced expression of 26 hydrolytic enzymes (putative CWDE and proteases) were the major reason for the approximately $90 \%$ reduction in mutant virulence.

Plant infection by fungi is characterized by the catabolism of internal lipid stores in the early stage and by the use of readily available external sugars and amino acids during the middle stage of infection (Solomon et al. 2003). Relatively little is known about the major nutrient sources of fungal metabolism during the late stage of infection. The regulation of CWDE expression is orchestrated by SNF1 homologs in two distantly related fungi (Ospina-Giraldo et al. 2003; Tonukari et al. 2000). A kinase $c c S N F 1$ in $C$. carbonum regulates a suite of CWDE genes during pathogenesis. Its mutants were less able to digest the main components of the host plant's cell walls and had a severe reduction in virulence. However, the primary role of genes regulated by $c c S N F 1$ was in the penetration of host leaves, not in utilization of plant materials as nutrients. Unlike $\Delta c c s n f 1$ mutants, the $\Delta a b v f 19$ mutant was similar to wild-type A. brassicicola in its appressorium-like structure formation and leaf penetration. Although we did observe somewhat shorter germination tubes in the $\Delta a b v f 19$ mutants, the main difference in our study was in the much smaller lesions caused by mutants compared with the wild type.

\section{Specialized hydrolytic enzyme genes for pathogenesis.}

Hydrolytic enzyme-coding genes with reduced expression in the mutant during late infection represented only a few genes within each gene family. For example, only 1 of 9 cutinase genes, 15 of 171 glycoside hydrolase genes, 6 of 235 peptidases, and 5 of 18 pectate lyase genes were downregulated in the mutant during late-stage infection (Table 2). The vegetative growth rate of the mutant was similar to the wild type in an axenic broth medium containing either glucose as a major carbon source or yeast extract as a major nitrogen source (Fig. 3).

Table 2. Downregulated genes in the $\Delta$ abvf19 mutant of Alternaria brassicicola

\begin{tabular}{lcc}
\hline Gene function & $\begin{array}{c}\text { Downregulated } \\
\text { in mutant }\end{array}$ & $\begin{array}{c}\text { Total numbers } \\
\text { in the genome }\end{array}$ \\
\hline Glycoside hydrolase & 14 & 171 \\
Pectate lyase & 5 & 18 \\
Pectinesterase & 1 & 4 \\
Cutinases & 1 & 9 \\
Peptidases & 6 & 235 \\
P450 & 4 & 79 \\
Ribonucleases & 2 & 19 \\
Unknown $^{\mathrm{a}}$ & 26 & 6,008 \\
Miscellaneous $^{\mathrm{b}}$ & 14 & 4317 \\
Total & 74 & 10,680 \\
\hline
\end{tabular}

${ }^{a}$ Genes in this category were annotated with hypothetical protein-coding genes that do not have similar sequences with known functions.

${ }^{\mathrm{b}}$ Genes in this category were annotated with functions that we did not see meaningful connections among their functions. 
This result suggested that $A b V f 19$ and its downstream hydrolytic enzyme genes were not associated with utilization of these nutrients derived from non-plants. The slower growth of the mutant than the wild type in the presence of pectin as a major carbon source suggested that these genes encode proteins important in depolymerizing plant substrates for use as nutrients. Similarly, some hydrolytic enzymes, such as extracellular proteases, cellulases, and xylanases, are dominantly expressed during late-stage infection in other phytopathogenic fungi (Dean et al. 2005; Hane et al. 2007).

\section{Importance of a coordinated expression of individual genes.}

Downregulated genes in the $\Delta a b v f 19$ mutant included $C b h 7$ and a chymotrypsin-coding gene that showed 21- and 2.6 times fewer transcripts, respectively, than wild-type A. brassicicola. These genes were previously known to be induced during pathogenesis (Cho et al. 2007; Cramer et al. 2006; Lev and Horwitz 2003). They were considered important for pathogenesis based on their highly elevated expression level. However, mutation of the chymotrypsin-coding gene $(C b h 7)$ did not lead to a significant reduction in virulence (Y. Cho, unpublished data). Similarly, the cutinase gene (CutAbl) had 73 times fewer transcript in the $\Delta a b v f 19$ mutant in this study but cutabl mutants in a previous study did not affect virulence (Yao and Köller 1995). These mutation studies suggested that each enzyme-coding gene either contributed little $(<5 \%)$ to virulence or their functions were redundant, as proposed previously based on $c c S N F 1$ and foSNF1 studies (Ospina-Giraldo et al. 2003; Tonukari et al. 2000). Regardless of the functional relationship among the products of each gene, the current $\Delta a b v f 19$ mutant study supports the importance of coordinated regulation of those genes during pathogenesis.

\section{Mechanistic roles of AbVf19.}

We expected AbVf19-GFP fusion proteins to be localized only during the late stage of infection or in the presence of pectin in an axenic medium. However, the proteins were consistently localized in wild-type $A$. brassicicola during all stages of plant infection and during saprophytic growth in axenic media containing either glucose or pectin. Deletion of this gene affected only pathogenicity, not saprophytic growth in axenic media containing nutrients derived from non-host plants. These two contrasting results suggested that the regulatory functions of AbVf19 depended on either its modification or the presence of cofactors, and that localization of the protein in the nuclei was insufficient for the regulation of virulenceassociated genes.

The transcription factor binding motif (Fig. 6) was compatible with cutinase expression data. Only one of nine genes in the family had a putative cis-element shared among downregulated genes and its expression level was 73 times lower in the mutant than in the wild type. The other eight cutinase genes did not have the binding motif and were not differentially expressed. However, the same binding site was not compatible with pectate lyase expression. We have not found a correlation between the presence or absence of this motif and the differential expression of pectate lyase. The AbVf19 proteins might have required additional transcription factors (cofactors) and each cofactor acted as a determinant for the regulation of downstream genes. Many hydrolytic enzymes are sequentially induced in A. brassicicola during pathogenesis (Fan and Köller 1998; Thomma 2003). The AbVf19 proteins may be involved in sequential regulation of a range of genes with the aid of various cofactors. Regardless of the regulation mechanisms of AbVF19, its amino acid sequence is highly conserved among Alternaria spp. but highly divergent from animal transcription factors. It is a potential target for the control of plant-pathogenic species of Alternaria, with little or no impact on animals.

\section{MATERIALS AND METHODS}

\section{Transformation, maintenance}

of fungal strains, and primers.

Growth and maintenance of the fungus and its transformation, nucleic acid isolation, mutant purification, and mutant verification by Southern hybridization were performed as described previously (Cho et al. 2009). Three probes for Southern hybridization were produced. Wild-type $A$. brassicicola and each of the mutant strains created during this study were purified by two rounds of single-spore isolation to obtain a more uniform genetic background. The cultures were maintained as glycerol stock in separate tubes, with one tube used for each assay. All primers used in this study are listed in Supplementary Table 3 .

\section{Determination of the full-length sequence.}

Using the partial sequence of the AbVfl9 gene in the draft annotated genome sequence, we designed one primer, AbVf19Fseq, in the coding region of the gene at the end of the contig. Another primer, AbVf19Rseq, was designed at the adjacent contig. These two primers were used to amplify the gap between the two contigs. The PCR products were used as template DNA and the sequence was determined with the two PCR primers. The sequence data have been deposited in the National Center for Biotechnology Information (NCBI) GenBank database (JN835469).

\section{Generation of deletion mutants for $A b V f 19$.}

All transformation constructs described in this work were produced by a double-joint PCR method (Yu et al. 2004), with modifications described previously (Cho et al. 2009). We made AbVf19 deletion mutants by replacing the gene with a HygB cassette. The replacement construct was produced with the following three sets of primers. The primer set P1 and P2 and the primer set P5 and P6 were used to amplify the 5' and 3' flanking regions, respectively, of the targeted locus. Another set of primers, $\mathrm{P} 3$ and $\mathrm{P} 4$, was used to amplify the HygB-selectable marker gene cassette $(1,436 \mathrm{bp})$ from pCB1636. The final transformation constructs were produced by PCR amplification using the mix of products from three reactions as template DNA and two primers, P1 and P6 (Supplementary Fig. S3).

\section{Generation of mutants expressing AbVf19-GFP fusion proteins.}

In order to create mutants expressing GFP fused to the C terminal of AbVf19, the AbVf19 coding region (1,209 bp) and 3' flanking region (192 bp) were amplified with $\mathrm{P} 1$ ' and $\mathrm{P} 2$ ', and P5 and P6', respectively. Another set of primers, P3' and $\mathrm{P} 4$, was used to amplify the $2,384 \mathrm{bp}$ that covered the coding regions of the GFP and the HygB cassette. The final transformation constructs were produced by PCR amplification from the mixture of the PCR products using $\mathrm{P}^{\prime}$ and $\mathrm{P}^{\prime}$.

\section{Complementation of the $\Delta a b v f 19$ mutants.}

The $\Delta a b v f 19$ mutant was complemented with the wild-type $A b V f 19$ allele with its native promoter. We used two primers to reintroduce wild-type $A b V f 19$ into the $\triangle a b v f 19-8$ mutant, $1 \mathrm{zAbVf19-5F}$ and $6 \mathrm{z} 9219-3 \mathrm{R}$. These primers amplified the 4,200-bp wild-type allele of the AbVf19 gene using A. brassicicola genomic DNA as a template. The PCR product included a 1,223-bp 5' flanking region, 1,747-bp complete coding region, and a 1,230-bp $3^{\prime}$ flanking region. Separately, pNR-20F and pNR-775R were used to amplify a 2,226-bp-long nourseo- 
thricin-resistant cassette as a selectable marker gene, using a pNR vector as the template (Malonek et al. 2004). These two products ( $7 \mu \mathrm{g}$ of $A b V f 19$ and $3 \mu \mathrm{g}$ of $N T C$ cassette) were mixed to transform the $\triangle a b v f 19$ mutant. Complemented mutant clones were purified by two rounds of single-spore isolation.

\section{Pathogenicity assays.}

Pathogenicity assays were performed on either whole plants or detached leaves harvested from 5- to 8-week-old B. oleracea (green cabbage) or Arabidopsis thaliana. A. thaliana plants included the Columbia ecotype and its pad3 mutant (Zhou et al. 1999). For most detached-leaf assays, leaves were removed, placed in mini-moist chambers, and randomly located on a laboratory bench. For the pathogenicity assays on whole plants, potted plants were placed in a semitransparent plastic trough with adequate water. The troughs with plants inside were sealed with saran wrap after inoculation to keep the relative humidity close to $100 \%$. The decreased virulence of each mutant was calculated using the formula $[\Sigma(\mathrm{Dw} i-\mathrm{Dm} i) / \Sigma(\mathrm{Dw} i)] \times 100$, where Dw $i$ was the lesion diameter created by the wild-type for the $i$ th sample and Dmi was the lesion diameter produced by the mutant for the $i$ th sample.

\section{Confocal microscopy.}

Infected plant tissues were trimmed with a razor blade, placed on microscope slides, and covered with Gold Seal cover glasses. Confocal images were acquired using a $633 \mathrm{C}$ Apochromat (numerical aperture 1.2) water-immersion objective lens and an Olympus Fluoview 1000 Laser Scanning Confocal System on an IX-81 inverted microscope. Spectra for fungal tissues expressing standard green fluorescence and for plant cells emitting autofluorescence were collected by simultaneous 488- and 543-nm excitation using 30-mW argon and 1-mW helium/neon lasers, respectively. The standard GFP spectrum was collected through 488-nm excitation using a 20nm window from 505 to $525 \mathrm{~nm}$. Plant tissue, including chloroplasts, was visualized using a 543-nm excitation with a 560nm-long pass filter. Images of fungal tissue grown in nutrient media were captured with 488-nm excitation and differential interference contrast (DIC)-transmitted light. All fluorescent images were composed of multiple layers acquired with the Confocal System.

\section{Synthetic media and vegetative growth assays.}

We made a minimal medium broth containing $0.5 \%$ $\left(\mathrm{NH}_{4}\right)_{2} \mathrm{SO}_{4}, 0.05 \%$ yeast extract, salts $\left(0.15 \% \mathrm{KH}_{2} \mathrm{PO}_{4}, 0.06 \%\right.$ $\mathrm{MgSO}_{4}$, and $0.06 \% \mathrm{CaCl}_{2}$ ), and trace amounts of metals $\left(0.0005 \% \quad \mathrm{FeSO}_{4} \quad 7 \mathrm{H}_{2} \mathrm{O}, 0.00016 \% \quad \mathrm{MnSO}_{4} \mathrm{H}_{2} \mathrm{O}, 0.00014 \%\right.$ $\mathrm{ZnSO}_{4} 7 \mathrm{H}_{2} \mathrm{O}$, and $\left.0.00037 \% \mathrm{CoCl}_{2}\right)$. Agar $(2 \% \mathrm{wt} / \mathrm{vol})$ was added to the broth to make MMA. Flasks $(250 \mathrm{ml})$ containing $50 \mathrm{ml}$ of minimal medium broth were supplemented with either $1 \%$ glucose or $1 \%$ of another complex carbon source, such as $\alpha$-cellulose, xylan, or citrus pectin (Sigma-Aldrich, St. Louis). Each flask was inoculated with $5 \times 10^{5}$ conidia of either the $\Delta a b v f 19$ mutant or the wild type. The flasks were incubated in the dark at $25^{\circ} \mathrm{C}$ with continuous agitation at $100 \mathrm{rpm}$. Mycelia were harvested at 4 days postinoculation, washed with distilled water, and dried at $105^{\circ} \mathrm{C}$ overnight. The decrease in biomass of each mutant compared with the wild type was calculated using the formula [ $\Sigma(\mathrm{Ww} i-\mathrm{Wm} i) /$ $\Sigma(\mathrm{Ww} i)] \times 100$, where Wwi was the dry weight of the wild type for the $i$ th sample and $\mathrm{Wm} i$ was the weight of the mutant for the $i$ th sample.

\section{RNA-seq data generation and gene expression analysis.}

Nine detached leaves harvested from three plants were inoculated with $10 \mu \mathrm{l}$ of water containing either 1,500 conidia from the $\Delta a b v f 19$ mutant or 1,500 conidia from the wild type. Tissue samples containing both host plant tissue and fungal hyphae were harvested and immediately frozen in liquid nitrogen to fix gene expression profiles. The frozen tissues were ground and total RNA was extracted using an RNeasy kit. Residual DNA was digested in columns with RNase-free DNase following the manufacturer's protocol (Qiagen, Palo Alto, CA, U.S.A.). Three biological replicates were prepared for the mutant and three for the wild type and their gene expression profiles compared.

We constructed strand-specific sequencing libraries using the TruSeq small RNA Sample Prep Kit (Illumina, San Diego, CA, U.S.A.) from total RNA following the manufacturer's protocol and size selecting libraries in $4 \%$ agarose gels to obtain fragment sizes between 100 and 150 bases in length. Each sample RNA was used to construct a library with a unique index primer. In total, six index primers were used to construct six libraries. All six libraries were mixed and determined 40 nucleotide-long sequence tags using Illumina Hiseq2000 (Illumina) according to the manufacturer's protocols. Image analysis, base-calling, and quality checks were performed with the Illumina data analysis pipeline CASAVA v1.8.0. The sequence data have been deposited in NCBI's Gene Expression Omnibus (GEO) (Edgar et al. 2002) and are accessible through GEO Series accession number GSE33148.

The sequenced reads were mapped to the genome sequence of $A$. brassicicola and the UniGene sequences of $B$. oleracea using the programs Tophat 1.3.1 (Trapnell et al. 2009) and Bowtie 0.12.7 (Langmead et al. 2009). Default settings were used, with these exceptions: the segment length was set at 20 nucleotides and the number of allowed segment mismatches was set at 1 nucleotide. Additionally, intron length was designated as a minimum of 10 nucleotides and a maximum of 400 nucleotides. The program Cuffdiff (version 1.0.3, part of Cufflinks) (Trapnell et al. 2010) was used to identify reads overlapping with previously predicted genes. The expression levels of each predicted gene were determined and normalized by the mapped FPKM. Differentially expressed genes between the wild type and the mutant were determined by comparing FPKM from three biological replicates for both the wild type and the mutant. We also applied a cutoff of at least a twofold change in expression value for differential expression. The bias correction method was used while running Cuffdiff (Roberts et al. 2011). Custom scripts were written in Python to analyze the data.

\section{Representation analysis.}

Custom scripts were developed in Python and $\mathrm{R}$ to analyze over- and underrepresentation of functional annotation terms in sets of differentially regulated genes using the Fisher Exact test. The Benjamini-Hochberg correction was used to correct for multiple testing using a $P$ value of 0.05 .

\section{Identification of transcription factor binding sites.}

MEME Suite 4.5.0 (Bailey and Elkan 1994) was used to identify conserved motifs in the promoters of genes. Promoters are defined here as the nucleotide sequence $750 \mathrm{bp}$ upstream of the translation start site of predicted genes. Incomplete promoters (with less than $750 \mathrm{bp}$ of available sequence or containing gaps) were excluded from the analysis. Parameters were chosen to identify conserved motifs of up to 10 nucleotides, with zero or one expected occurrence in each promoter on both strands. The nucleotide frequencies of all promoters were used as background frequencies. The identified motifs were manually inspected. Next, occurrences of the relevant motifs in the full promoter set were counted using FIMO, which is part of the MEME Suite. Significance of overrepresentation of the 
identified motifs in the promoter subset was determined with the Fisher Exact test. To identify the similarity of the identified motifs with previously published motifs, TOMTOM (part of the MEME Suite) (Gupta et al. 2007) was used to search the JASPAR CORE database of transcription factor-binding profiles (Bryne et al. 2008).

\section{qRT-PCR.}

The $\Delta a b v f 19$ mutant and wild type were used for qRT-PCR. Total RNA $(2 \mu \mathrm{g})$ was transcribed to cDNA in a final volume of $20 \mu \mathrm{l}$ using $50 \mathrm{ng}$ of random pentamers and $200 \mathrm{ng}$ of poly $(\mathrm{T})_{20} \mathrm{~N}$ with Superscript III (Invitrogen, Carlsbad, CA, U.S.A.). Each cDNA was diluted 1:20. Subsequent qRT-PCR reactions were performed in a $20-\mu \mathrm{l}$ volume containing $120 \mathrm{nM}$ each primer, $1 \mu \mathrm{l}$ of diluted cDNA, and $10 \mu \mathrm{l}$ of FastStart SYBRGreen Master (Roche, Mannheim, Germany). Each reaction was run in triplicate in a Bio-Rad I-cycler (Bio-Rad, Hercules, CA, U.S.A.) as described previously (Cho et al. 2006). Relative amounts of the transcript of each gene were calculated as $2^{-\Delta \mathrm{Ct}}$ using a threshold cycle $(\mathrm{Ct})$, where $\Delta \mathrm{Ct}=(\mathrm{Ct}$, gene $i$ $\mathrm{Ct}$,actin). Fold changes of each gene between the wild type and $\Delta$ amrl strain were calculated as $2^{-\Delta \Delta \mathrm{Ct}}$, where $\Delta \Delta \mathrm{Ct}=(\mathrm{Ct}$,genei $\left.\mathrm{Ct} \mathrm{t}_{\text {actin }}\right) \Delta_{\text {abvfl9 }}-\left(\mathrm{Ct} \mathrm{t}_{\text {genei }}-\mathrm{Ct} \text {,actin }\right)_{\text {wild type }}$

\section{ACKNOWLEDGMENTS}

We thank T. M. Carvalho, W. Borth, A. Alvarez, and J. Hu for generously sharing their research equipment. This research was supported by United States Department of Agriculture TSTAR 2009-34135-20197 and HATCH funds to Y. Cho, administered by the College of Tropical Agriculture and Human Resources, University of Hawaii at Manoa, Honolulu. Analysis of RNA-seq data and downstream analyses were done by the U.S. Department of Energy Joint Genome Institute that is supported by the Office of Science of the U.S. Department of Energy under contract number DE-AC02-05CH11231.

\section{LITERATURE CITED}

Bailey, T. L., and Elkan, C. 1994. Fitting a mixture model by expectation maximization to discover motifs in biopolymers. Proc. Int. Conf. Intell. Syst. Mol. Biol. 2:28-36.

Bateman, A., Coin, L., Durbin, R., Finn, R.D., Hollich, V., Griffiths-Jones, S., Khanna, A., Marshall, M., Moxon, S., Sonnhammer, E. L., Studholme, D. J., Yeats, C., and Eddy, S. R. 2004. The Pfam protein families database. Nucleic Acids Res. 32:D138-141.

Bryne, J. C., Valen, E., Tang, M. H., Marstrand, T., Winther, O., da Piedade, I., Krogh, A., Lenhard, B., and Sandelin, A. 2008. JASPAR, the open access database of transcription factor-binding profiles: New content and tools in the 2008 update. Nucleic Acids Res. 36:D102-106.

Cho, Y., Davis, J. W., Kim, K. H., Wang, J., Sun, Q. H., Cramer, R. A. J., and Lawrence, C. B. 2006. A high throughput targeted gene disruption method for Alternaria brassicicola functional genomics using linear minimal element (LME) constructs. Mol. Plant-Microbe Interact. 19:7-15.

Cho, Y., Cramer, R. A., Jr., Kim, K. H., Davis, J., Mitchell, T. K., Figuli, P., Pryor, B. M., Lemasters, E., and Lawrence, C. B. 2007. The Fus3/Kss1 MAP kinase homolog Amk1 regulates the expression of genes encoding hydrolytic enzymes in Alternaria brassicicola. Fungal Genet. Biol. 44:543-553.

Cho, Y., Kim, K.-H., La Rota, M., Scott, D., Santopietro, G., Callihan, M., and Lawrence, C. B. 2009. Identification of virulence factors by high throughput targeted gene deletion of regulatory genes in Alternaria brassicicola. Mol. Microbiol. 72:1316-1333.

Churchill, A., Lu, S., Turgeon, B., Yoder, O., and Macko, V. 1995. Victorin-deficient REMI mutants of Cochliobolus victoriae demonstrate a requirement for victorin in pathogenesis. Fungal Genet. Newsl. 42A:41.

Ciuffetti, L., Tuori, R., and Gaventa, J. 1997. A single gene encodes a selective toxin causal to the development of tan spot of wheat. Plant Cell 9:135-144.

Cramer, R. A., La Rota, C. M., Cho, Y., Thon, M., Craven, K. D., Knudson, D. L., Mitchell, T. K., and Lawrence, C. B. 2006. Bioinformatic analysis of expressed sequence tags derived from a compatible Alternaria brassicicola-Brassica oleracea interaction. Mol. Plant Pathol. 7:113-124.

Dean, R. A., Talbot, N. J., Ebbole, D. J., Farman, M. L., Mitchell, T. K.,
Orbach, M. J., Thon, M., Kulkarni, R., Xu, J. R., Pan, H., Read, N. D., Lee, Y. H., Carbone, I., Brown, D., Oh, Y. Y., Donofrio, N., Jeong, J. S., Soanes, D. M., Djonovic, S., Kolomiets, E., Rehmeyer, C., Li, W., Harding, M., Kim, S., Lebrun, M. H., Bohnert, H., Coughlan, S., Butler, J., Calvo, S., Ma, L. J., Nicol, R., Purcell, S., Nusbaum, C., Galagan, J. E., and Birren, B. W. 2005. The genome sequence of the rice blast fungus Magnaporthe grisea. Nature 434:980-986.

Del Sorbo, G., Scala, F., Parrella, G., Lorito, M., Comparini, C., Ruocco, M., and Scala, A. 2000. Functional expression of the gene cu, encoding the phytotoxic hydrophobin cerato-ulmin, enables Ophiostoma quercus, a nonpathogen on elm, to cause symptoms of Dutch elm disease. Mol. Plant-Microbe Interact. 13:43-53.

Edgar, R., Domrachev, M., and Lash, A. E. 2002. Gene Expression Omnibus: NCBI gene expression and hybridization array data repository. Nucleic Acids Res. 30: 207-211.

Fan, C.-Y., and Köller, W. 1998. Diversity of cutinases from plant pathogenic fungi: Differential and sequential expression of cutinolytic esterases by Alternaria brassicicola. FEMS (Fed. Eur. Microbiol. Soc.) Microbiol. Lett. 158:33-38.

Gupta, S., Stamatoyannopoulos, J. A., Bailey, T. L., and Noble, W. S. 2007. Quantifying similarity between motifs. Genome Biol. 8:R24.

Hane, J. K., Lowe, R. G., Solomon, P. S., Tan, K. C., Schoch, C. L., Spatafora, J. W., Crous, P. W., Kodira, C., Birren, B. W., Galagan, J. E., Torriani, S. F., McDonald, B. A., and Oliver, R. P. 2007. Dothideomycete plant interactions illuminated by genome sequencing and EST analysis of the wheat pathogen Stagonospora nodorum. Plant Cell 19:3347-3368.

Hashimoto, M., Higuchi, Y., Takahashi, S., Osada, H., Sakaki, T., Toyomasu, T., Sassa, T., Kato, N., and Dairi, T. 2009. Functional analyses of cytochrome $\mathrm{P} 450$ genes responsible for the early steps of brassicicene C biosynthesis. Bioorg. Med. Chem. Lett. 19:5640-5643.

Horton, P., and Nakai, K. 1997. Better prediction of protein cellular localization sites with the $\mathrm{k}$ nearest neighbors classifier. Proc. Int. Conf. Intell. Syst. Mol. Biol. 5:147-152.

Ito, K., Tanaka, T., Hatta, R., Yamamoto, M., Akimitsu, K., and Tsuge, T. 2004. Dissection of the host range of the fungal plant pathogen Alternaria alternata by modification of secondary metabolism. Mol. Microbiol. 52:399-411.

Iuchi, S. 2001. Three classes of $\mathrm{C}_{2} \mathrm{H}_{2}$ zinc finger proteins. Cell Mol. Life Sci. 58:625-635.

Johnson, R. D., Johnson, L., Itoh, Y., Kodama, M., Otani, H., and Kohmoto, K. 2000. Cloning and characterization of a cyclic peptide synthetase gene from Alternaria alternata apple pathotype whose product is involved in AM-toxin synthesis and pathogenicity. Mol. Plant-Microbe Interact. 13:742-753.

Langmead, B., Trapnell, C., Pop, M., and Salzberg, S. L. 2009. Ultrafast and memory-efficient alignment of short DNA sequences to the human genome. Genome Biol. 10:R25.

Lev, S., and Horwitz, B. A. 2003. A mitogen-activated protein kinase pathway modulates the expression of two cellulase genes in Cochliobolus heterostrophus during plant infection. Plant Cell 15:835-844.

Lorang, J. M., Tuori, R. P., Martinez, J. P., Sawyer, T. L., Redman, R. S., Rollins, J. A., Wolpert, T. J., Johnson, K. B., Rodriguez, R. J., Dickman, M. B., and Ciuffetti, L. M. 2001. Green fluorescent protein is lighting up fungal biology. Appl. Environ. Microbiol. 67:1987-1994.

Malonek, S., Rojas, M. C., Hedden, P., Gaskin, P., Hopkins, P., and Tudzynski, B. 2004. The NADPH-cytochrome P450 reductase gene from Gibberella fujikuroi is essential for gibberellin biosynthesis. J. Biol. Chem. 279:25075-25084.

Narusaka, Y., Narusaka, M., Seki, M., Ishida, J., Nakashima, M., Kamiya, A., Enju, A., Sakurai, T., Satoh, M., Kobayashi, M., Tosa, Y., Park, P., and Shinozaki, K. 2003. The cDNA microarray analysis using an Arabidopsis pad3 mutant reveals the expression profiles and classification of genes induced by Alternaria brassicicola attack. Plant Cell Physiol. 44:377-387.

Oh, I. S., Park, A. R., Bae, M. S., Kwon, S. J., Kim, Y. S., Lee, J. E., Kang, N. Y., Lee, S., Cheong, H., and Park, O.K. 2005. Secretome analysis reveals an Arabidopsis lipase involved in defense against Alternaria brassicicola. Plant Cell 17:2832-2847.

Oka, K., Akamatsub, H., Kodamab, M., Nakajimab, H., Kawadab, T., and Otani, H. 2005. Host-specific AB-toxin production by germinating spores of Alternaria brassicicola is induced by a host-derived oligosaccharide. Physiol. Mol. Plant Pathol. 66:12-19.

Ospina-Giraldo, M. D., Mullins, E., and Kang, S. 2003. Loss of function of the Fusarium oxysporum SNF1 gene reduces virulence on cabbage and Arabidopsis. Curr. Genet. 44:49-57.

Otani, H., Kohnobe, A., Kodama, M., and Kohmoto, K. 1998. Production of a host-specific toxin by germinating spores of Alternaria brassicicola. Physiol. Mol. Plant Pathol. 52:285-295.

Pedras, M. S., Chumala, P. B., Jin, W., Islam, M. S., and Hauck, D. W. 
2009a. The phytopathogenic fungus Alternaria brassicicola: Phytotoxin production and phytoalexin elicitation. Phytochemistry 70:394402.

Pedras, M. S., Minic, Z., and Sarma-Mamillapalle, V. K. 2009b. Substrate specificity and inhibition of brassinin hydrolases, detoxifying enzymes from the plant pathogens Leptosphaeria maculans and Alternaria brassicicola. FEBS (Fed. Eur. Biochem. Soc.) J. 276:7412-7428.

Roberts, A., Trapnell, C., Donaghey, J., Rinn, J. L., and Pachter, L. 2011. Improving RNA-Seq expression estimates by correcting for fragment bias. Genome Biol. 12:R22.

Seidl, V., Seiboth, B., Karaffa, L., and Kubicek, C. P. 2004. The fungal STRE-element-binding protein Seb1 is involved but not essential for glycerol dehydrogenase ( $g l d l)$ gene expression and glycerol accumulation in Trichoderma atroviride during osmotic stress. Fungal Genet. Biol. 41:1132-1140.

Sexton, A. C., Minic, Z., Cozijnsen, A. J., Pedras, M. S., and Howlett, B.J. 2009. Cloning, purification and characterisation of brassinin glucosyltransferase, a phytoalexin-detoxifying enzyme from the plant pathogen Sclerotinia sclerotiorum. Fungal Genet. Biol. 46:201-209.

Solomon, P. S., Tan, K. C., and Oliver, R. P. 2003. The nutrient supply of pathogenic fungi; a fertile field for study. Mol. Plant Pathol. 4:203-210.

Spassieva, S. D., Markham, J. E., and Hille, J. 2002. The plant disease resistance gene Asc-1 prevents disruption of sphingolipid metabolism during AAL-toxin-induced programmed cell death. Plant J. 32:561-572.

Tanaka, A., Shiotani, H., Yamamoto, M., and Tsuge, T. 1999. Insertional mutagenesis and cloning of the genes required for biosynthesis of the host-specific AK-toxin in the Japanese pear pathotype of Alternaria alternata. Mol. Plant-Microbe Interact. 12:691-702.

Thomma, B. P., Nelissen, I., Eggermont, K., and Broekaert, W..F. 1999. Deficiency in phytoalexin production causes enhanced susceptibility of Arabidopsis thaliana to the fungus Alternaria brassicicola. Plant J. Cell Mol. Biol. 19:163-171.

Thomma, B. P. H. J. 2003. Alternaria spp.: From general saprophyte to specific parasite. Mol. Plant Pathol. 4:225-236.

Tonukari, N. J., Scott-Craig, J. S., and Walton, J. D. 2000. The Cochliobolus carbonum SNF1 gene is required for cell wall-degrading enzyme expression and virulence on maize. Plant Cell 12:237-248.
Trapnell, C., Pachter, L., and Salzberg, S. L. 2009. TopHat: Discovering splice junctions with RNA-Seq. Bioinformatics 25:1105-1111.

Trapnell, C., Williams, B. A., Pertea, G., Mortazavi, A., Kwan, G., Van Baren, M. J., Salzberg, S. L., Wold, B. J., and Pachter, L. 2010. Transcript assembly and quantification by RNA-Seq reveals unannotated transcripts and isoform switching during cell differentiation. Nat. Biotechnol. 28:511-515.

Wight, W. D., Kim, K. H., Lawrence, C. B., and Walton, J. D. 2009. Biosynthesis and role in virulence of the histone deacetylase inhibitor depudecin from Alternaria brassicicola. Mol. Plant-Microbe Interact. 22:1258-1267.

Wong Sak Hoi, J., and Dumas, B. 2010. Ste12 and Ste12-like proteins, fungal transcription factors regulating development and pathogenicity. Eukaryot. Cell 9:480-485.

Yao, C., and Köller, W. 1995. Diversity of cutinases from plant pathogenic fungi: Different cutinases are expressed during saprophytic and pathogenic stages of Alternaria brassicicola. Mol. Plant-Microbe Interact. 8:122-130.

Yu, J. H., Hamari, Z., Han, K. H., Seo, J. A., Reyes-Dominguez, Y., and Scazzocchio, C. 2004. Double-joint PCR: A PCR-based molecular tool for gene manipulations in filamentous fungi. Fungal Genet. Biol. 41:973-981.

Yun, S.-H., Turgeon, B., and Yoder, O. 1998. REM-induced mutants of Mycosphaerella zeae-maydis lacking the polyketide PM-toxin are deficient in pathogenesis to corn. Physiol. Mol. Plant Pathol. 52:53-66.

Zhou, N., Tootle, T. L., and Glazebrook, J. 1999. Arabidopsis PAD3, a gene required for camalexin biosynthesis, encodes a putative cytochrome P450 monooxygenase. Plant Cell 11:2419-2428.

\section{AUTHOR-RECOMMENDED INTERNET RESOURCES}

Department of Energy Alternaria brassicicola genome portal page: jgi.doe.gov/Abrassicicola

NCBI GEO database: www.ncbi.nlm.nih.gov/geo/info/linking.html

UniGene sequence repository for Brassica oleracea: ftp.ncbi.nih.gov/repository/UniGene/Brassica_oleracea 